\title{
The Nogo-66 Receptor NgR1 Is Required Only for the Acute Growth Cone-Collapsing But Not the Chronic Growth- Inhibitory Actions of Myelin Inhibitors
}

\author{
Onanong Chivatakarn, ${ }^{1,2}$ Shinjiro Kaneko, ${ }^{3}$ Zhigang He, ${ }^{3}$ Marc Tessier-Lavigne, ${ }^{4}$ and Roman J. Giger ${ }^{2}$ \\ ${ }^{1}$ Interdepartmental Graduate Program in Neuroscience, ${ }^{2}$ Center for Aging and Developmental Biology, Department of Biomedical Genetics, University of \\ Rochester School of Medicine and Dentistry, Rochester, New York 14642, ${ }^{3}$ Division of Neuroscience, Children's Hospital and Program in Neuroscience, \\ Harvard Medical School, Boston, Massachusetts 02115, and ${ }^{4}$ Division of Research, Genentech, Inc., South San Francisco, California 94080
}

\begin{abstract}
Neuronal Nogo-66 receptor 1 (NgR1) has been proposed to function as an obligatory coreceptor for the myelin-derived ligands Nogo-A, oligodendrocyte myelin glycoprotein $(\mathrm{OMgp})$, and myelin-associated glycoprotein (MAG) to mediate neurite outgrowth inhibition by these ligands. To examine the contribution of neuronal NgR1 to outgrowth inhibition, we used two different strategies, genetic ablation of $\mathrm{NgR} 1$ through the germline and transient short hairpin RNA interference (shRNAi)-mediated knock-down. To monitor growth inhibition, two different paradigms were used, chronic presentation of substrate-bound inhibitor to measure neurite extension and acute application of soluble inhibitor to assay growth cone collapse. We find that regardless of the $\mathrm{NgR} 1$ genotype, membrane-bound MAG strongly inhibits neurite outgrowth of primary cerebellar, sensory, and cortical neurons. Similarly, substrate-bound OMgp strongly inhibits neurite outgrowth of $\mathrm{NgR} 1$ wild-type and mutant sensory neurons. Consistent with these results, shRNAi-mediated knock-down of neuronal NgR1 does not result in a substantial release of L-MAG (large MAG) inhibition. When applied acutely, however, MAG-Fc and OMgp-Fc induce a modest degree of growth cone collapse that is significantly attenuated in NgR1-null neurons compared with wild-type controls. Based on our findings and previous studies with Nogo-66, we propose that neuronal NgR1 has a circumscribed role in regulating cytoskeletal dynamics after acute exposure to soluble MAG, OMgp, or Nogo-66, but is not required for these ligands to mediate their growth-inhibitory properties in chronic outgrowth experiments. Our results thus provide unexpected evidence that the growth conecollapsing activities and substrate growth-inhibitory activities of inhibitory ligands can be dissociated. We also conclude that chronic axon growth inhibition by myelin is mediated by NgR1-independent mechanisms.
\end{abstract}

Key words: neurite outgrowth; growth cone collapse; MAG; OMgp; shRNAi; myelin

\section{Introduction}

Neurological deficits as a consequence of spinal cord injury are primarily the result of lost neuronal connectivity between neurons located proximal and distal to the injury site. The inability of injured neurons to restore lost connectivity leads to permanent neurological deficits. The lack of spontaneous neuronal repair is believed to be in part a reflection of the growth-inhibitory properties of adult CNS myelin.

Myelin-associated inhibitors include Nogo-A, a member of the reticulon family, myelin-associated glycoprotein (MAG), a member of the Siglec family of sialic acid binding Ig-like lectins,

Received April 5, 2007; revised May 23, 2007; accepted May 25, 2007.

This work was supported by National Institutes of Health Training Grant T32 MH065181 and National Research Service Award Ruth Kirschstein Fellowship F31NS056558 (0.C.), New York State Spinal Cord Injury Research Program, Ellison Medical Foundation, and National Institute of Neurological Disorders and Stroke Grant NS047333 (R.J.G.). We thank D. Welch for excellent technical assistance, S. Strittmatter and B. Liu for sharing DRG growth cone collapse protocols, H. Lee for PC12(NgR1) cells, C. Rader for anti-NgR1 lgG, M. Filbin for providing CHO-MAG and CHO cell lines, R. Quarles for anti-MAG, and D. Lee for Nogo-66 and OMgp protein.

Correspondence should be addressed to Dr. Roman J. Giger, University of Rochester School of Medicine and Dentistry, 601 Elmwood Avenue, Rochester, NY 14642. E-mail: roman giger@urmc.rochester.edu.

DOI:10.1523/JNEUROSCI.1541-07.2007

Copyright $\odot 2007$ Society for Neuroscience $\quad$ 0270-6474/07/277117-08\$15.00/0 and oligodendrocyte myelin glycoprotein (OMgp), a glycosylphosphatidylinositol (GPI)-anchored member of the LRR (leucine-rich repeat) family of proteins (Liu et al., 2006). Although structurally distinct, each of these three inhibitors binds with high affinity to Nogo-66 receptor 1 (NgR1), a GPIanchored, $65 \mathrm{kDa}$ glycoprotein (Fournier et al., 2001; Domeniconi et al., 2002; Liu et al., 2002; Wang et al., 2002a). NgR1 has been proposed to function as the ligand binding component of a tripartite receptor system that also includes Lingo- 1 and the tumor necrosis factor (TNF) receptor family members p $75^{\text {NTR }}$ or TROY (Liu et al., 2006). In support of the hypothesis that neuronal NgR1 has a central role in signaling myelin inhibition are gain-of-function studies showing that ectopic NgR1 can confer growth inhibition on neurons normally not responsive to myelin inhibitors (Fournier et al., 2001; Liu et al., 2002; Wang et al., 2002a). Conversely, introduction of a dominant-negative form of NgR1 into neurons (Domeniconi et al., 2002), application of soluble NgR1 that retains ligand binding capacity (Fournier et al., 2002), or peptide inhibitors (NEP1-40) of the Nogo/NgR1 interaction (Li and Strittmatter, 2003) each have been shown to antagonize neurite outgrowth elicited by individual myelin inhibitors or crude CNS myelin in vitro. Perturbation of NgR1 with 
function-blocking antibodies (Domeniconi et al., 2002; Li et al., 2004) or short hairpin RNA interference (shRNAi)-mediated knock-down (Ahmed et al., 2005) have been reported to support the model that NgR1 is essential for Nogo-66, OMgp, and MAG inhibition.

Using a mouse genetic approach, the importance of $\mathrm{NgR} 1$ as a converging point for several myelin inhibitors that signal growth arrest has recently been examined more directly. In one study, germline ablation of $\mathrm{NgR} 1$ was found to attenuate growth cone collapse induced by soluble Nogo-66, MAG, OMgp, or CNS myelin in postnatal day 14 dorsal root ganglion (DRG) neurons (Kim et al., 2004). In an independent study, neurite extension of NgR1-null neurons on immobilized Nogo-66 or CNS myelin substrate was examined. Surprisingly, neither postnatal cerebellar granule neurons (CGNs) nor DRG neurons of NgR1-null mice were found to be more resistant to Nogo-66 or CNS myelinelicited growth inhibition than their wild-type littermate controls (Zheng et al., 2005). This result strongly suggests that Nogo-66 can signal growth inhibition through NgR1-independent mechanisms. Because neuronal NgR1 has been proposed to represent a convergence point for multiple inhibitors, we used $\mathrm{NgR} 1$-null neurons or shRNAi-mediated depletion of $\mathrm{NgR} 1$ to examine to what extent NgR1 contributes to inhibitory responses to MAG and OMgp. Here, we provide evidence that NgR1 is important for MAG- and OMgp-elicited growth cone collapse but is dispensable for MAG- or OMgp-mediated inhibition of longitudinal neurite outgrowth. These results are consistent with and extend the findings that $\mathrm{NgR} 1$ is required for acute collapse-inducing effects of Nogo-66 (Kim et al., 2004) but not for its ability to inhibit axon outgrowth when presented as a substrate (Zheng et al., 2005). Together, our studies and previous studies indicate that an NgR1-independent mechanism mediates the chronic growth-inhibitory actions of myelin inhibitors.

\section{Materials and Methods}

Neurite outgrowth assays. To assay for MAG-mediated growth inhibition, primary neurons from wild-type and $\mathrm{NgR} 1$ mutant pups (Zheng et al., 2005) were cultured for $18-20 \mathrm{~h}$ on confluent monolayers of CHO cells that either express recombinant large MAG (L-MAG) on their surface or on CHO cells lacking L-MAG (Venkatesh et al., 2005). Images of TuJ1positive cells (Promega, Madison, WI) were taken using an Olympus (Tokyo, Japan) IX71 inverted microscope attached to a DP70 digital camera, and neurite length was quantified using UTHSCSA ImageTool for Windows. Neurites equal to or longer than approximately one cell body diameter were measured. For all experiments, the mean and SEM of neurite length were determined from multiple independent experiments; for MAG inhibition, CGNs, wild-type $(n=5)$, and $N g R 1^{-1-}(n=5)$; for DRGs, wild-type $(n=5)$; and for $N g R 1^{-1-}(n=5)$. The genotype of mice was determined by PCR (Zheng et al., 2005), and mutants were confirmed by anti-NgR1 immunoblotting. To assay neuronal responses to substrate-bound Nogo-66 and OMgp, postnatal day 25 (P25) DRG neurons, wild-type $(n=3)$ and $\mathrm{NgR} 1$ mutant $(n=3)$ DRGs were dissected and incubated with $0.3 \%$ collagenase and $0.25 \%$ trypsin. DRG neurons were plated onto 96-well plates coated with poly-D-lysine (PDL) (50 $\mu \mathrm{g} / \mathrm{ml}$; Sigma, St. Louis, MO) and laminin (10 $\mu \mathrm{g} / \mathrm{ml}$; Invitrogen, San Diego, CA) and recombinant myelin inhibitor as described (Sivasankaran et al., 2004). Briefly, nitrocellulose was dissolved in methanol and used to coat 96-well plates. The optimal concentration of recombinant inhibitor was determined by serial dilution. For DRG neurons, final concentrations of Nogo-66 $(\sim 2 \mu \mathrm{g} /$ well $)$ or OMgp $(\sim 1 \mu \mathrm{g} /$ well $)$ were used. DRG neurons were plated at a density of $2 \times 10^{3}$ cells/well and cultured for $18 \mathrm{~h}$ in Neurobasal A media (Invitrogen) supplemented with B27 (Invitrogen) and NGF (50 ng/ml; Promega). Statistical analyses of neurite length were done using Student's $t$ test.

To examine whether lowering the concentration of substrate-bound
MAG leads to a significant difference in growth inhibition between wildtype and NgR1-null neurons, P7 CGNs were plated on serial dilutions of MAG membranes. Briefly, cells were scraped from culture plates and homogenized in ice-cold PBS containing protease inhibitor mixture (Sigma). Cell homogenates from two confluent $10 \mathrm{~cm}$ plates of $\mathrm{CHO}$ control or CHO-MAG cells were isolated using a low-speed spin $(1000 \times$ $g$; $5 \mathrm{~min}$ ) and the resulting supernatant was incubated in $60 \mathrm{~mm}$ CHAPS (3-[(3-cholamidopropyl)dimethylammonio]-1-propanesulfonate) on ice for $30 \mathrm{~min}$ to extract membrane proteins as described (Venkatesh et al., 2005). After high-speed centrifugation, the protein concentration of cleared membrane proteins was determined using a BCA kit (Venkatesh et al., 2005). CHO control and CHO-MAG membrane extracts were then mixed at different ratios, including $\mathrm{CHO}-\mathrm{MAG}$ and $\mathrm{CHO}$ extracts only. Membrane proteins $(1 \mu \mathrm{g} / \mu \mathrm{l})$ were adsorbed to poly-lysine-coated cell culture dishes, blocked by incubation with fatty acid-free BSA $(0.1 \mathrm{mg} /$ $\mathrm{ml})$ for $30 \mathrm{~min}$, and incubated with laminin $(1 \mu \mathrm{g} / \mathrm{ml})$ for $1 \mathrm{~h}$ at room temperature. CGNs from $\mathrm{P} 7$ wild-type and $\mathrm{NgR}^{-1-}$ pups were isolated in a discontinuous Percoll gradient, cultured for $24 \mathrm{~h}$ in SATO + medium, and analyzed for neurite lengths as described (Venkatesh et al., 2005).

Growth cone collapse assay. DRGs were isolated from 3- to 4-week-old wild-type or $\mathrm{NgR}^{-1-}$ mutant mice, cut with a small scalpel into four to six smaller pieces, and cultured for $3 \mathrm{~d}$ on PDL $(100 \mu \mathrm{g} / \mathrm{ml})$ - and laminin $(10 \mu \mathrm{g} / \mathrm{ml})$-coated four-well plates. DRG explants that showed robust fiber growth were incubated in MAG-Fc ( $100 \mathrm{~nm}$; R\&D Systems, Minneapolis, MN) oligomerized with anti-human Fc (Promega); OMgp-Fc (6 nM; Biogen Idec, Cambridge, MA) oligomerized with anti-human Fc; AP-Sema3A (10 nм) (Giger et al., 1998); or Neurobasal medium (Invitrogen). For oligomerization, fusion proteins were preincubated with anti-Fc for $30 \mathrm{~min}$ at a ratio of 3:1. Growth cone collapse was assayed 30 min after bath application of inhibitor and visualized by phalloidinrhodamine labeling. Several independent rounds of growth cone collapse assays were performed. If the baseline of collapsed growth cones in Neurobasal-treated cultures was $>50 \%$ (negative control) or the Sema3A-induced growth cone collapse was not statistically significant (positive control), the assay was discarded and parallel cultures treated with MAG-Fc or OMgp-Fc were not included in the quantification. The number of independent experiments meeting these criteria were as follows: for MAG-Fc, $n=6$ wild-type and $n=6 \mathrm{NgR}^{-1-}$; for OMgp-Fc, $n=9$ wild-type and $n=10 \mathrm{NgR}^{-1-}$; for Sema3A, $n=15$ wild-type and $n=16 \mathrm{NgR1}^{-1-}$; and for Neurobasal, $n=15$ wild-type and $n=16$ $N g R 1^{-1-}$.

NgR1 RNAi knock-down. For shRNAi knock-down of rat NgR1, PC12 cells stably overexpressing NgR1 or embryonic day 18.5 (E18.5) rat cortical neurons were transfected using the basic nucleofection solution for primary neural cells (VPI-1003; Amaxa, Gaithersburg, MD) with either a mixture of $3 \mu \mathrm{l}$ of enhanced green fluorescent protein (eGFP) plasmid $(0.5 \mu \mathrm{g} / \mu \mathrm{l})$ and $1 \mu \mathrm{l}$ of $(20 \mu \mathrm{M})$ stock rat NgR1 shRNAi (catalog no. M-080084-00; Dharmacon, Lafayette, CO) or $3 \mu \mathrm{l}$ of eGFP plasmid (0.5 $\mu \mathrm{g} / \mu \mathrm{l})$ only. Transfected neurons were grown for $3 \mathrm{~d}$, changing the medium once. On the third day, some of the transfected cells were either directly lysed in Laemmli buffer to monitor NgR1 knock-down by Western blotting or gently trypsinized, rinsed in $10 \% \mathrm{FBS}$, and grown on CHO-MAG or CHO control feeder cells for $18 \mathrm{~h}$ (Venkatesh et al., 2005). Neurite length of eGFP-positive neurons on feeder cells was quantified as described above. NgR1 expression in eGFP-positive neurons was monitored by anti-NgR1 immunofluorescence (Hofer et al., 2007). As a comparison, we also assayed for MAG-mediated neurite outgrowth inhibition of cortical neurons obtained from three litters of E18.5 mouse embryos, resulting in a total of wild-type $(n=12), \mathrm{NgR}^{+/-}(n=12)$, and $\mathrm{NgRl}^{-1-}(n=13)$ cultures.

Quantitative analysis of neurite length. All fluorescence pictures were taken with an IX71 Olympus Inverted Microscope attached at the side to a DP70 digital camera. For quantification of neurite length, pictures of dissociated DRGs, CGNs, or cortical neurons with processes equal to or longer than approximately one cell body diameter were taken. Neurite length was measured from digitized images using UTHSCSA Image Tool for Windows, version 3.0. The mean and SEM of neurite-bearing cells were calculated from at least three to six independent experiments. Data 

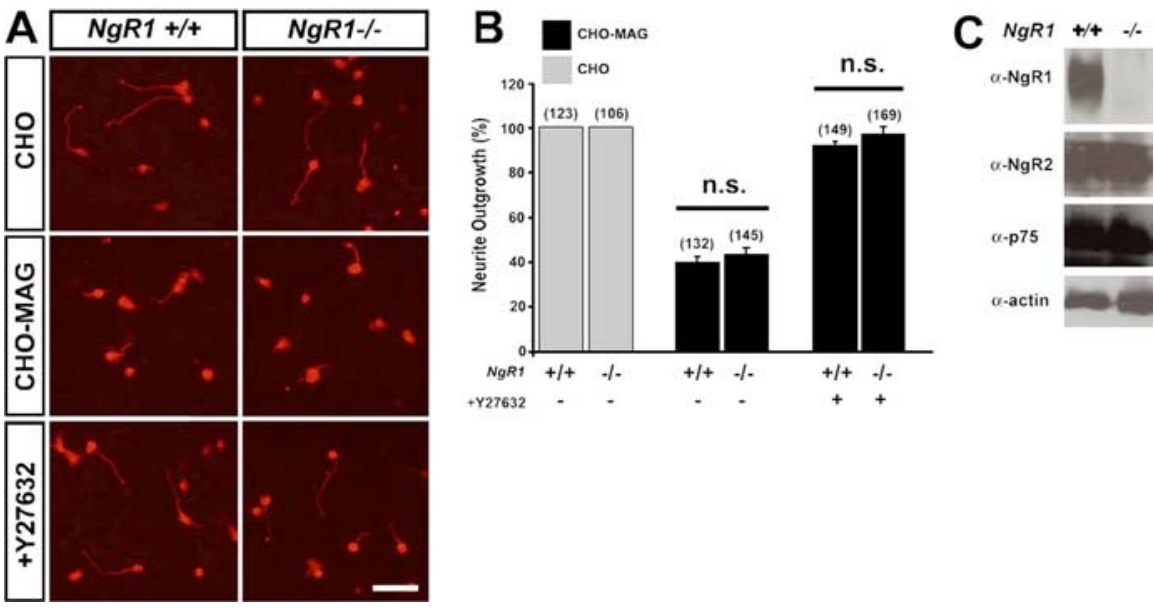

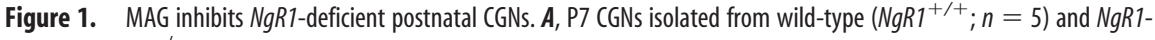
deficient $\left(\mathrm{NgR1}^{-1-} ; n=5\right)$ mice were cultured on CHO control or CHO-MAG feeder layers and stained with TuJ1. Scale bar, 50 $\mu \mathrm{m} . \mathrm{B}$, Quantification of neurite lengths on $\mathrm{CHO}$ (gray bars) and CHO-MAG cells (black bars) revealed strong inhibition of both wild-type and $\mathrm{NgR1}^{-1-}$ neurons on CH0-MAG cells $(p<0.05)$. MAG inhibition is fully reversed in the presence of Y27632 $[(R)-(+)$-trans- $N$-(4-pyridyl)-4-(1-aminoethyl)-cyclohexanecarboxamide] $(20 \mu \mathrm{M})$. The number of neurites quantified for each condition is indicated in parentheses. Results are presented as mean \pm SEM from five independent experiments, and the percentile of neurite outgrowth compared with $\mathrm{CHO}$ controls is shown. No significant difference (n.s.) in neurite length is observed between wild-type and NgR1-deficient neurons cultured on CHO-MAG cells. Wild-type and $\mathrm{NgR}^{-/-}$CGNs show robust and very similar growth on control CHO feeder cells [Kruskal-Wallis one-way ANOVA ( post hoc Dunn's test)]. C, Western blot analysis for $\mathrm{NgR} 1, \mathrm{NgR} 2$, and p75 ${ }^{\mathrm{NTR}}$ normalized to actin in P7 brain lysates of wild-type and $\mathrm{NgR} 1$ mutants. In wild-type brains, NgR1 protein is detected at an apparent molecular weight of $65 \mathrm{kDa}$. No $\mathrm{NgR} 1$ protein is detected in brain lysates of $\mathrm{NgR1}{ }^{-/-}$mice. Loss of $\mathrm{NgR1}$ does not result in altered expression levels of $\mathrm{NgR2}$ or p75 protein.

were analyzed by Student's $t$ test or one-way ANOVA followed by Dunn's post hoc analysis or Student's $t$ test using SigmaSTAT 3.0. All error bars shown indicate SEM.

\section{Results}

\section{L-MAG inhibits neurite outgrowth of NgR1-null and wild-type neurons}

To examine whether $N g R 1$ is important for MAG-elicited neurite outgrowth inhibition, primary neurons isolated from wild-type and $\mathrm{NgR} 1$-null mice were plated on CHO-MAG feeder cells stably expressing L-MAG or on CHO control cells that do not express MAG. Postnatal CGNs from wild-type and $\mathrm{NgR} 1$-null mice show robust and comparable neurite outgrowth on $\mathrm{CHO}$ control cells. Independent of their genotype, however, neurite outgrowth on CHO-MAG cells is strongly inhibited. Quantification of neurite lengths revealed a decline in fiber length of $60 \%$ for wild-type CGNs and $57 \%$ for $\mathrm{NgR1}^{-/-}$CGNs. The difference in neurite length between wild-type and $\mathrm{NgR} 1^{-/-}$CGNs is not statistically significant (Fig. $1 A, B$ ). Loss of NgR1 protein in $N g R 1$-null mice was confirmed by immunoblotting of postnatal brain lysates (Fig. $1 C)$. Consistent with our previous results in the rat (Venkatesh et al., 2005), anti-NgR1 selectively detects a $65 \mathrm{kDa}$ protein in wildtype but not $\mathrm{NgR1}$-deficient mouse brain. No change in expression of NgR2 or p $75^{\mathrm{NTR}}$ protein levels was observed in $\mathrm{NgR} 1$ mutants (Fig. 1C). To probe an independent neuronal cell type, we assayed MAG inhibition of postnatal DRG neurons isolated from wild-type and $\mathrm{NgR} 1^{-/-}$mice. We found that, regardless of the genotype, DRG neurite length on CHO-MAG was significantly inhibited compared with $\mathrm{CHO}$ controls (supplemental Fig. 1, available at www.jneurosci.org as supplemental material). In the presence of the Rho kinase inhibitor, Y27632, MAG inhibition of wild-type and $\mathrm{NgR} 1^{-/-}$CGNs was fully reversed (Fig. $1 B)$. As an additional control, we asked whether lowering the MAG dose results in a difference in growth inhibition between wild-type and $\mathrm{NgRl}^{-1-}$ neurons. As shown in supplemental Fig. 2 (available at www.jneurosci.org as supplemental material), stepwise dilution of $\mathrm{CHO}-\mathrm{MAG}$ membranes with control $\mathrm{CHO}$ membranes, when presented as substrate, results in a gradual release of inhibition of CGNs; however, no difference in inhibition between wild-type and $N g R 1^{-1-}$ neurons was observed at any dilution of MAG examined.

Together, these observations imply that $N g R 1$ is not important for MAG-elicited neurite outgrowth inhibition of CGNs or DRGs. Furthermore, because the MAG receptor NgR2 is not expressed in postnatal CGNs (Venkatesh et al., 2005), this implies the existence of NgR1- and NgR2independent mechanisms to signal MAG inhibition.

\section{$N g R 1$ is dispensable for OMgp- mediated inhibition of neurite extension}

Next, we examined whether neurite outgrowth inhibition on substrate-bound OMgp is $N g R 1$ dependent. Postnatal day 25 DRGs of wild-type and $N g R 1^{-/-}$mice were cultured on OMgp substrate, and neurite outgrowth was assessed after $20 \mathrm{~h}$. As a control, we also included Nogo-66-coated plates. Similar to MAG (Fig. 1) and consistent with the study by Zheng et al. (2005), genetic ablation of $N g R 1$ does not attenuate Nogo-66mediated neurite outgrowth inhibition. Furthermore, there was no difference in neurite length between wild-type and $\mathrm{NgR} 1^{-1-}$ neurons cultured on OMgp substrate (Fig. 2). Wild-type DRG neurons grown on control substrate show robust neurite outgrowth, but neurite length of wild-type DRGs on Nogo-66 or OMgp substrate is decreased by 43 and 47\%, respectively (Fig. $2 B)$. A very similar decrease in neurite length was observed with $\mathrm{NgR}^{-/-}$DRG neurons. Compared with control substrate, neurite length of $\mathrm{NgR}^{-1-}$ DRG neurons on Nogo-66 or OMgp substrate was decreased by 46 and $50 \%$, respectively (Fig. $2 B$ ). Together, our data show that $N g R 1$ is not necessary for Nogo-66 or OMgp substrate inhibition and imply the existence of $\mathrm{NgR} 1$ independent mechanisms for Nogo-66- and OMgp-elicited neurite outgrowth inhibition.

\section{shRNAi-mediated knock-down of NgR1 does not attenuate L-MAG inhibition}

As an independent approach to functionally ablate neuronal $\mathrm{NgR} 1$, we used an shRNAi-based approach in rat embryonic cortical neurons (Fig. 3). To monitor NgR1 knock-down at the cellular level, eGFP plasmid DNA (pEGFP) was either transfected alone or cotransfected with NgR1 shRNAi. NgR1 knock-down in cotransfected neurons was assayed by anti-GFP and anti-NgR1 double immunofluorescence (Fig. 3A). Neurons transfected with pEGFP alone were positive for GFP and NgR1. In cotransfected cultures, neurons that stained for GFP did not label with anti$\mathrm{NgR} 1$, indicating significant knock-down of NgR1 protein (Fig. $3 A)$. As an independent control, PC12 cells stably expressing $\mathrm{NgR} 1\left(\mathrm{PC} 12^{\mathrm{NgR} 1}\right.$ ) and primary E18.5 cortical neurons were lysed $3 \mathrm{~d}$ after shRNAi transfection and analyzed by anti-NgR1 immu- 

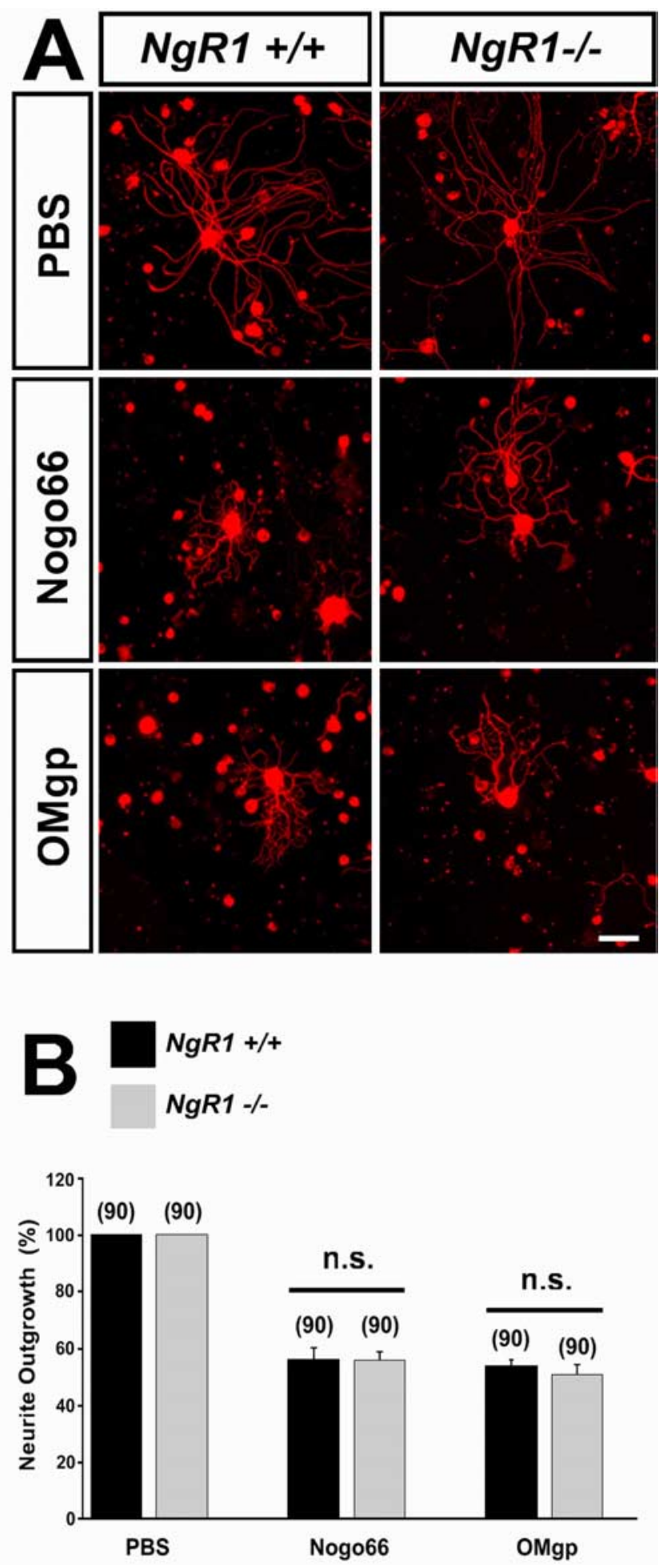

Figure 2. $\mathrm{NgR1}$ is dispensable for OMgp-mediated inhibition of neurite extension. $\boldsymbol{A}$, Postnatal day $25 \mathrm{DRG}$ neurons of wild-type $\left(\mathrm{NgR1^{+/+ }} ; n=3\right)$ and $\mathrm{NgR1}$ mutants $\left(\mathrm{NgR1^{-/- }} ; n=\right.$ 3) were either cultured on control substrate (PDL/laminin) or plates also containing recombinant Nogo-66 or 0Mgp. Neurons were labeled by TuJ1 immunofluorescence. Scale bar, 100 $\mu \mathrm{m} . \boldsymbol{B}$, Quantification of neurite lengths of wild-type (black bars) and $\mathrm{NgR1^{-1- }}$ (gray bars) neurons. Compared with control substrate, Nogo-66 and 0Mgp substrates significantly inhibit growth of DRG neurons from wild-type mice (Nogo-66, $p=0.006$; 0Mgp, $p=0.003$ ) and

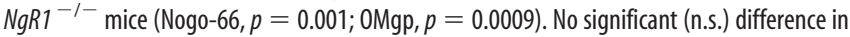
neurite outgrowth between wild-type and $\mathrm{NgR} 1$ mutant DRGs was observed. Results are presented as mean \pm SEM from three independent experiments, and the number of neurites quantified for each condition is indicated in parentheses. Statistical analyses were done using Student's $t$ test. noblotting. As shown in Figure $3 B$, shRNAi in PC12 ${ }^{\mathrm{NgR} 1}$ cells and cortical neurons revealed a strong reduction in $\mathrm{NgR} 1$ expression. Transfection efficiencies of 30-50\% were achieved (Venkatesh et al., 2005) and, accordingly, did not result in a complete loss of $\mathrm{NgR} 1$ in cell culture lysates (Fig. $3 B$ ).

Importantly, when assayed for neurite outgrowth on $\mathrm{CHO}$ MAG cells, no difference in neurite length between control (eGFP only) and shRNAi-transfected (eGFP plus shRNAi) cortical neurons was observed (Fig. 3C). Thus, independent of their NgR1 expression levels, cortical neurons are strongly inhibited on $\mathrm{CHO}-\mathrm{MAG}$ but not $\mathrm{CHO}$ feeder cells. In a parallel experiment, we used mouse cortical neurons isolated from wild-type and $N g R 1$-null mutants and found that $N g R 1$ is not necessary for MAG inhibition (Fig. 3D). Thus, shRNAi-mediated knock-down of $\mathrm{NgR} 1$ is in agreement with our data obtained with primary neurons isolated from $N g R 1$ mutant mice. Together, our data show that neither germline ablation of $N g R 1$ nor transient, shRNAi-mediated gene knock-down of NgR1 leads to a significant disinhibition of neurite outgrowth on MAG substrate.

\section{MAG-Fc- and OMgp-Fc-induced growth cone collapse is attenuated in $\mathrm{NgR} 1$-null DRG neurons}

Thus far, our studies indicate that functional depletion of NgR1 does not result in enhanced neurite outgrowth on membranebound MAG (Fig. 1). Furthermore, $N g R 1$ is not necessary for neurite outgrowth inhibition on substrate-bound Nogo-66 (Zheng et al., 2005) or OMgp (Fig. 2). Our findings may appear at odds with a previous study reporting that $N g R 1$ is important to bring about inhibition by Nogo-66, OMgp, and MAG (Kim et al., 2004). However, Kim et al. (2004) did not examine the effects of removing NgR1 on growth-inhibitory substrates. Rather, they assayed growth cone collapse of wild-type and $\mathrm{NgR}^{-1-} \mathrm{DRG}$ neurons to monitor neuronal responses to individual myelin inhibitors. Because growth cone collapse and substrate inhibition could, in principle, involve different mechanisms, we examined whether growth cone collapse induced by MAG-Fc or OMgp-Fc is attenuated in DRG neurons of our independently generated NgR1-null mouse (Zheng et al., 2005). One limitation of the growth cone collapse assay with postnatal DRG neurons is a high baseline of collapsed growth cones. Consistent with Kim et al. (2004), we find that $\sim 40-45 \%$ of growth cones are collapsed in the absence of any exogenously added inhibitor (Fig. 4). As a positive control to monitor growth cone collapse, DRG explants were treated with Semaphorin 3A (Sema3A) (Reza et al., 1999). Sema3A induced a rapid and significant increase in the number of collapsed growth cones in both wild-type and $\mathrm{NgR}^{-1-}$ neurons (Fig. 4). The baseline of collapsed growth cones was similarly high for wild-type $(40 \pm 3 \%)$ and $N g R 1^{-1-}(45 \pm 2 \%)$ DRGs and increased in the presence of $10 \mathrm{nM}$ Sema3A to $82 \pm 3 \%$ for wildtype and to $79 \pm 3 \%$ for $N g R 1^{-1-}$ DRG explants. A more modest but still significant increase in growth cone collapse was observed in wild-type DRGs after acute application of soluble MAG. The number of collapsed growth cones increased to $65 \pm 4 \%$ in the presence of $100 \mathrm{nM}$ MAG-Fc in wild-type cultures $(p<0.001)$. In contrast, MAG did not cause a statistically significant increase in growth cone collapse of $\mathrm{NgR} 1^{-1-}$ DRGs (change from $45 \pm 2 \%$ without MAG to $48 \pm 3 \%$ with MAG) (Fig. 4). In a parallel experiment, DRG explants were treated with $6 \mathrm{~nm}$ OMgp-Fc. Wild-type DRG cultures exposed to OMgp-Fc showed a significant increase in growth cone collapse $(65 \pm 4 \% ; p<0.001)$. Under similar conditions, OMgp-Fc failed to induce growth cone collapse in DRG explants from $N g R 1^{-l-}$ mice ( $44 \pm 5 \%$ ). Thus, after acute application of soluble MAG-Fc or OMgp-Fc, 

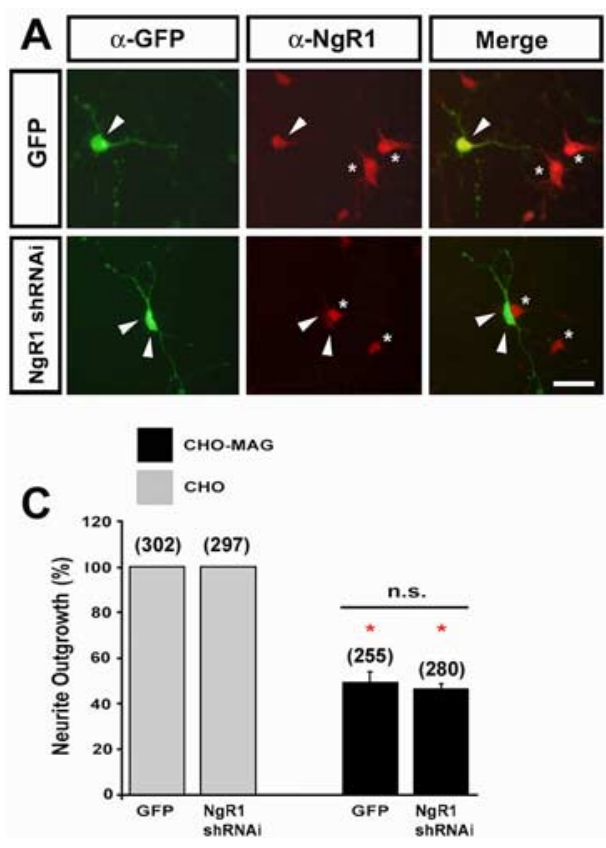

Figure 3. shRNAi knock-down of NgR1 in cortical neurons does not release MAG inhibition. $\boldsymbol{A}$, Cortical neurons of E18.5 rats were either transfected with pEGFP alone or pEGFP and shRNAi using the Amaxa nucleofection technology. Three days after transfection, $\mathrm{NgR1}$ expression in GFP ${ }^{+}$neurons was analyzed by anti-NgR1 and anti-GFP double-immunofluorescence labeling. The single arrowheads indicate a transfected neuron that is $\mathrm{GFP}^{+}$and $\mathrm{NgR}^{+}{ }^{+}$; the double arrowheads indicate transfected neurons with successful knock-down of NgR1. The asterisks show untransfected NgR1 ${ }^{+}$neurons. Scale bar, $50 \mu \mathrm{m}$. $\boldsymbol{B}$, Western blot analysis for NgR1 of PC12 ${ }^{\mathrm{NgR} 1}$ cells and primary cortical neurons either transfected with pEGFP or double-transfected with pEGFP plus NgR1 shRNAi. Lysates of NgR1-shRNAi transfected cells show a decrease in total NgR1 expression. Actin immunoblotting is shown as a loading control. C, Quantification of neurite outgrowth on CHO (gray bars) and CHO-MAG (black bars) feeder cells of GFP ${ }^{+}$neurons of pEGFP transfected and pEGFP plus shRNAi double-transfected cultures revealed strong and comparable inhibition. D, E18.5 cortical neurons of wild-type $\left(\mathrm{NgR1^{+/+ }}\right)$ and mutant $\left(\mathrm{NgR}^{-/-}\right)$mice are strongly inhibited on CH0-MAG feeder cells. Results are presented as mean \pm SEM from six independent experiments for shRNAi. ${ }^{*} p<0.05$, significantly different from neurons grown on $\mathrm{CHO}$ feeder cells; n.s. indicates that there was no significant difference in neurite growth between control and NgR1-depleted neurons [Kruskal-Wallis one-way ANOVA ( post hoc Dunn's test)].

$N g R 1^{-1-}$ DRG neurons no longer show a significant growth cone collapse response, consistent with the absence of a collapsing effect of Nogo-66, MAG, and OMgp on DRG neurons from NgR1 knock-out mice (Kim et al., 2004). Together, these results indicate that NgR1 is required only for acute collapsing effects of the inhibitory ligands, but not for their ability to inhibit when presented as substrates in a chronic outgrowth assay.

\section{Discussion}

The Nogo-66 receptor NgR1 supports high-affinity binding of three potent myelin-associated inhibitors of neurite outgrowth, (namely, Nogo-A, OMgp, and MAG) and neuronal NgR1 has been proposed to serve as an important convergence point for inhibitory responses toward each of its ligands. Recently, two independent groups used a mouse genetic approach to more directly test the hypothesis that $\mathrm{NgR} 1$ is essential for inhibitory responses toward its ligands (Kim et al., 2004; Zheng et al., 2005). At face value, the two studies seemed to come to opposite conclusions, but on closer examination there were important differences in the way the two studies were performed. Specifically, Kim et al. (2004) studied the modest growth cone-collapsing activity of NgR1 ligands when applied acutely to DRG neurons, and found that this required NgR1 function because it was not observed on DRG neurons from $\mathrm{NgR} 1$ knock-out mice. In contrast, Zheng et al. (2005) examined the axon growth-inhibitory activity of Nogo-66 and CNS myelin when presented as substrates for CGN and DRG neurons in chronic culture experi- ments, and found that $N g R 1$ was dispensable for this activity, thereby questioning the importance of NgR1 in myelin inhibition. Here, we reconcile these two studies by showing that NgR1 is required for acute collapsing effects of MAG and OMgp, but not for their ability to inhibit neurite outgrowth when presented as substrates.

Recent evidence suggests that different neuronal cell types use different mechanisms for MAG inhibition (Venkatesh et al., 2007); we therefore examined the contribution of $\mathrm{NgR} 1$ in MAG-mediated outgrowth inhibition in CGNs, DRGs, and cortical neurons. These are cell types commonly used to assay for CNS myelin inhibition; they all express NgR1 and include myelinated and nonmyelinated neurons. Each of these neuronal cell types isolated from wild-type mice is strongly inhibited by membrane-bound MAG. Furthermore, we found that neurite outgrowth of $\mathrm{NgR} 1$ deficient neurons is strongly inhibited on MAG and to a similar extent as for wildtype neurons. Thus, in three different neuronal cell types, loss of $\mathrm{NgR} 1$ does not reduce inhibition by membrane-bound MAG. In a similar vein, substrate-bound Nogo-66 and OMgp strongly inhibit neurite outgrowth of $\mathrm{NgR} 1^{-/-}$DRG neurons.

Although neither p $75^{\text {NTR }}$ nor NgR2 expression was altered in NgR1-null brain tissue, it remains possible that germline ablation of $\mathrm{NgR} 1$ leads to compensatory changes in gene expression that may influence signaling pathways regulating neuronal growth behavior. We therefore wanted to independently replicate our findings with $\mathrm{NgR} 1$-null neurons by acute shRNAi-mediated gene knock-down. Consistent with our studies with different populations of primary neurons from $\mathrm{NgR} 1$-null mice, we found no disinhibition of neurite outgrowth after shRNAi-mediated knock-down of NgR1 in cortical neurons cultured on CHO-MAG feeder cells. Thus, two different strategies used to functionally ablate $\mathrm{NgR} 1$, one chronic and one acute, failed to demonstrate any significant role for NgR1 in MAGmediated neurite outgrowth inhibition. Together with the previous finding that $\mathrm{NgR}^{-/-}$neurons are not disinhibited on Nogo-66 substrate (Zheng et al., 2005), these studies show that $\mathrm{NgR} 1$ is not important for Nogo-66-, OMgp-, or MAG-mediated neurite outgrowth inhibition in vitro.

An independent study by Ahmed et al. (2005), using an RNAibased approach to functionally deplete $\mathrm{NgR} 1$ in adult rat DRG neurons, found a significant release of neurite outgrowth inhibition in the presence of crude CNS myelin. We did not see a similar effect after acute shRNAi-mediated knock-down of NgR1 in primary cortical neurons cultured on MAG (Fig. 3). Although different neuronal populations may use different mechanisms to respond to CNS myelin, we also noticed several important differences between the two experiments. First, Ahmed et al. cultured DRG neurons in the presence of FGF2 $(10 \mathrm{ng} / \mathrm{ml})$ and the study did not address whether loss of NgR1 modulates FGF2 signaling rather than responsiveness to CNS myelin. Second, Ahmed et al. used soluble rat CNS myelin extracts of unknown composition, 

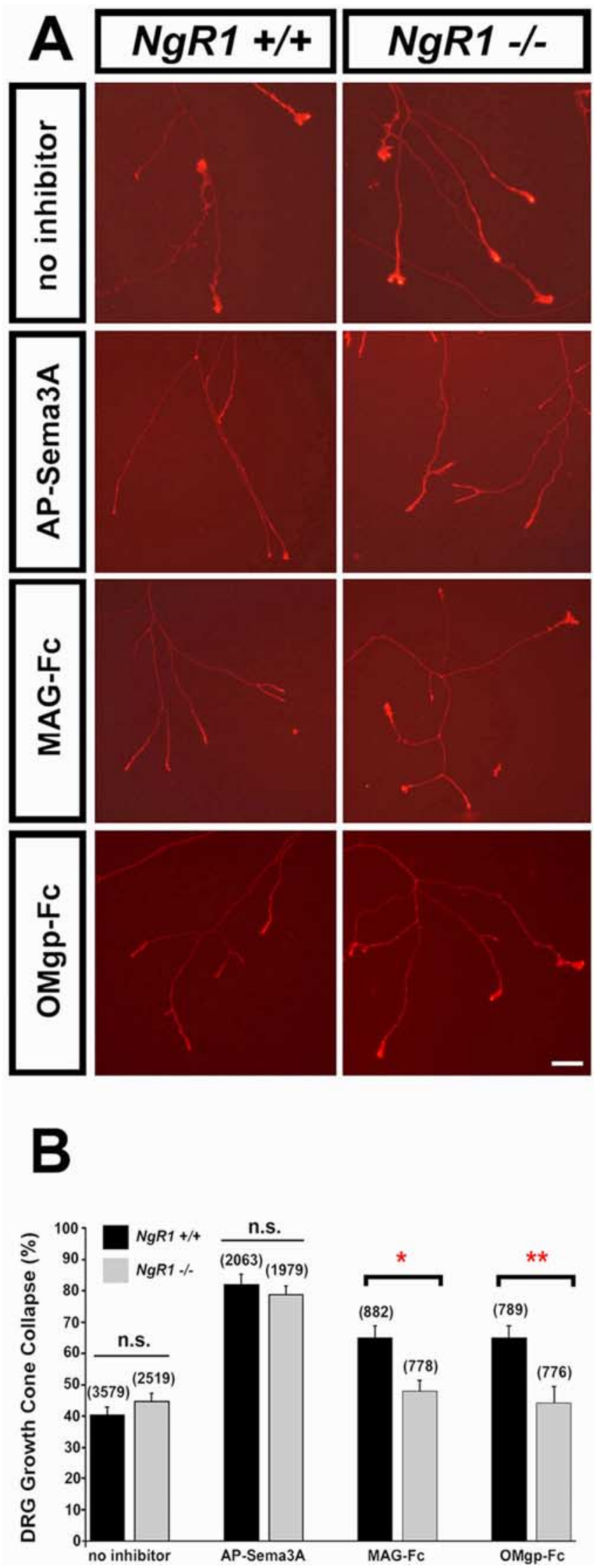

Figure 4. MAG- and OMgp-induced growth cone collapse is attenuated in NgR1-null neurons. $\boldsymbol{A}$, Growth cones of postnatal DRG explants of wild-type $\left(\mathrm{NgR}^{+/+}\right)$and $\mathrm{NgR1}$ mutant $\left(\mathrm{NgR1}^{-/-}\right)$mice were treated with no inhibitor, AP-Sema3A (10 nM), MAG-Fc (100 nm), or OMgp-Fc (6 nm) for $30 \mathrm{~min}$ and stained with rhodamine-conjugated phalloidin. Scale bar, 10 directly added to the culture medium to inhibit neurite growth. In the present study, we used membrane-bound MAG or substrate-bound recombinant OMgp or Nogo-66 to inhibit neurite outgrowth. Third, to monitor NgR1 knock-down, Ahmed et al. show Western blot analyses of DRG lysates $3 \mathrm{~d}$ after RNAi transfection and found a significant decrease of an $\sim 80 \mathrm{kDa}$ immunoreactive band. Western blot analysis of brain extracts from $\mathrm{NgR} 1$ mutant mice results in complete loss of an anti-NgR1 immunoreactive band with an apparent molecular weight of $65 \mathrm{kDa}$ (Fig. 1C). Consistent with this, we previously reported that endogenously expressed rat NgR1 has a molecular weight of $65 \mathrm{kDa}$ (Venkatesh et al., 2005). Thus, it is not clear whether in the study by Ahmed et al. (2005) proteins other than NgR1 were knockeddown by the RNAi constructs used (Ahmed et al., 2005). For a more complete assessment of whether acute loss of $N g R 1$ alters myelin-mediated neurite growth inhibition of different cell types, additional studies, including conditional ablation of $\mathrm{NgR} 1$, will be needed.

Here, we report that $N g R 1$ is not necessary for Nogo-66 (Zheng et al., 2005), OMgp, and MAG-mediated neurite outgrowth inhibition. The apparent disparity between these results and the results reported by Kim et al. (2004), using an independently generated $N g R 1$ knock-out mouse, appeared striking, but now appear to be related to differences in methods used to assay inhibition. Indeed, the conclusions made by Kim et al. are based on a DRG growth cone collapse assay, whereas our results are based on neurite outgrowth assays on substrate-bound inhibitor. Specifically, Kim et al. found that each of the three myelin inhibitors when applied acutely caused a modest increase in the collapse of wild-type DRG growth cones from $\sim 40$ to $\sim 60 \%$, an increase that was not seen with their $\mathrm{NgR} 1$-deficient neurons (Kim et al., 2004). Using the same assay and DRG neurons from our independently generated $N g R 1$-null mice, we found that, in the presence of MAG-Fc or OMgp-Fc, a significantly greater number of growth cones is collapsed in wild-type neurons compared with $\mathrm{NgR} 1$ mutant neurons. Moreover, in DRG neurons, $\mathrm{NgR} 1$ is important for MAG-Fc- or OMgp-Fc-induced growth cone collapse. Thus, neurons from two independently generated NgR1-null mouse lines behave very similarly when analyzed in the same assay, which strengthens our conclusion that NgR1 is important for growth cone responses after acute application of inhibitor, but is dispensable for neurite outgrowth inhibition on Nogo-66 (Zheng et al., 2005), MAG, and OMgp substrate.

Two homologs of NgR1 have been identified in the mouse genome, NgR2 and NgR3, raising the question of whether these proteins function as alternate receptors for myelin inhibitors. With respect to Nogo-66 or OMgp signaling, NgR2 and NgR3 are likely not to serve as functional substitutes for $\mathrm{NgR} 1$. This is primarily based on previous observations that Nogo-66 and OMgp selectively bind to NgR1 but do not bind to NgR2 or NgR3 (Barton et al., 2003). Although NgR2 has been found to support high-affinity MAG binding, its CNS distribution is overlapping,

$\mu \mathrm{m} . \boldsymbol{B}$, Quantification of collapsed growth cones. Results are presented as mean \pm SEM from 6-16 independent experiments with $\mathrm{NgRT}^{+/+}$(black bars) and $\mathrm{NgRT}^{-1-}$ (gray bars). For MAG-Fc, $n=6 \mathrm{NgRT}^{+/+}$and $n=6 \mathrm{NgR1}^{-/-}$; for 0Mgp-Fc, $n=9 \mathrm{NgR}^{+/+}$and $n=10$ $\mathrm{NgR1}^{-l-}$; for Sema3A, $n=15 \mathrm{NgR1}^{+/+}$and $n=16 \mathrm{NgR1}^{-l-}$; and for no inhibitor, $n=15$ $\mathrm{NgR1}^{+/+}$and $n=16 \mathrm{NgR1}^{-/-}$. The number of growth cones quantified for each condition is indicated in parentheses. ${ }^{*} p<0.001$, significant difference between $\mathrm{NgR1}{ }^{+/+}$and $\mathrm{NgR1} 1^{-1-}$ DRG neurons treated with MAG-Fc. ${ }^{* *} p<0.001$, significant difference between $N g R 1^{+/+}$and $\mathrm{NgR1}^{-1-}$ DRG neurons treated with OMgp-Fc [Kruskal-Wallis one-way ANOVA ( post hoc Dunn's test)]. 
yet distinct from NgR1 (Venkatesh et al., 2005; Barrette et al., 2007). For example, we have previously shown that NgR1 but not $\mathrm{NgR} 2$ is expressed in postnatal cerebellar granule neurons (Venkatesh et al., 2005). Furthermore, no upregulation of NgR2 expression is observed in $N g R 1$-null mice (Fig. $1 C$ ), and thus, MAG inhibition of $\mathrm{NgR} 1$-deficient CGNs is likely to be independent of $\mathrm{NgR} 1$ and NgR2. Adult DRG neurons show a heterogeneous expression of $\mathrm{NgR} 2$ (Venkatesh et al., 2005), but loss of $\mathrm{NgR} 1$ results in a significant attenuation of MAG-Fc-induced growth cone collapse, suggesting that NgR2 does not contribute significantly to the collapse-inducing response. To what extent NgR2 expressed in other neuronal populations participates in MAG inhibition is not known, and future studies with primary neurons from $\mathrm{NgR} 2$ mutant or $N g R 1$ and $N g R 2$ double knock-out mice will be needed.

Our results imply that some other receptor(s) must exist that can bind Nogo-66, MAG, and OMgp to mediate the actions of these factors in substrate inhibition. If so, how does NgR1 fit in with this alternate receptor(s)? A first possibility is that $\mathrm{NgR} 1$ pairs with this receptor(s) to increase its affinity for the inhibitory ligands. In this model, loss of NgR1 would reduce the sensitivity of the receptor, which could lead to loss of collapse but not substrate inhibition if the concentration of each ligand was limiting in the collapse assay but saturating in the substrate assay. Arguing strongly against this possibility, however, is our finding from a substrate dilution series that the degree of inhibition by different concentrations of MAG is the same for wild-type and $\mathrm{NgR} 1$ knock-out neurons (supplemental Fig. 2, available at www.jneurosci.org as supplemental material). Also, neurons from p75 knockout mice showed enhanced neurite outgrowth in similar experimental procedures (Wang et al., 2002b; Yamashita et al., 2002; Zheng et al., 2005). Instead, our results appear to imply that different mechanisms are required for collapse and for growth inhibition. This conclusion is unexpected, because it is widely assumed in the field that growth cone collapse-inducing activities simply reflect the effect of acute activation of an inhibitory receptor. Instead, the finding that myelin inhibitors can inhibit growth of $\mathrm{NgR}^{-1-}$ neurons without causing collapse of their growth cones shows that the two effects can be dissociated. How this occurs mechanistically is not clear, although one could imagine several ways in which differential effects could be generated; for example, one could speculate that the alternate receptor(s) impinges on mechanisms regulating protrusive activity of actin filaments or stabilization of microtubules, and that NgR1, either in collaboration with this receptor(s) or through some other means, is poised to trigger actin depolymerization. Elucidating the precise mechanism will require additional studies.

What are the implications of our findings for CNS regeneration? The role of the Nogo/NgR1 system in limiting neuronal growth and axonal regeneration after spinal cord injury is controversial (Cafferty et al., 2007; Steward et al., 2007). Two independent studies showed that germline ablation of $\mathrm{NgR} 1$ does not result in a significant regeneration of corticospinal tract axons after dorsal hemisection at T6 or complete transection at T8 (Kim et al., 2004) or dorsal hemisection at T8 (Zheng et al., 2005). Kim et al. (2004) reported regeneration of some raphespinal and rubrospinal fibers in $N g R 1$ mutants after dorsal hemisection. In a more recent study, it was found that pyramidotomy in $N g R 1$ mutants does not lead to long-distance axonal regeneration but induced growth of corticospinal tract axons into denervated cervical gray matter proximal to the injury site (Cafferty and Strittmatter, 2006). Consistent with the lack of long-distance axonal growth in spinal cord-injured $\mathrm{NgR} 1$ mutants in vivo, we report

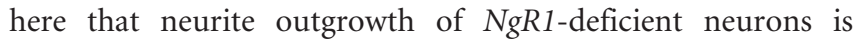
strongly inhibited by substrate-bound Nogo-66, OMgp, or MAG in vitro.

Several studies have reported positive behavioral effects in injured rodents after antagonism of $\mathrm{NgR} 1$ with peptide inhibitors of Nogo (GrandPre et al., 2002; Li and Strittmatter, 2003), soluble receptor bodies [NgR(310)Ecto-Fc] (Li et al., 2004; Wang et al., 2006), NgR1 DNA vaccination (Yu et al., 2007), or genetic ablation (Lee et al., 2004). Some of these manipulations had the potential to interfere with more than just NgR1, so caution must be exercised in interpreting these results. To the extent that behavioral improvement in some of these studies can be attributed specifically to antagonism of $\mathrm{NgR} 1$, the question arises whether the improvement is related to more subtle structural changes of the neuronal architecture, rather than long-distance axonal sprouting. Short-range morphological changes, including collateral sprouting, altered shape or number of dendritic spines, and number of synaptic contacts may be achieved primarily through remodeling of the actin cytoskeleton. Spines are small dendritic perturbations that represent postsynaptic sites of excitatory synaptic input and changes in spine number and morphology have been proposed to contribute to alterations in excitatory synaptic transmission (Lamprecht and LeDoux, 2004). Functional recovery, although often very limited, is observed after CNS traumatic injury or stroke and is believed, at least in part, to be a reflection of natural plasticity of uninjured neurons adjacent to denervated areas (Belhaj-Saif and Cheney, 2000; Raineteau and Schwab, 2001). Functional recovery can be enhanced by physiotherapy (exercise) as a natural and noninvasive paradigm to promote neuronal activity, which leads to increased expression of neurotrophic factors, enhanced plasticity, and rehabilitative gains (de Leon et al., 1998; Toni et al., 1999; Vaynman and Gomez-Pinilla, 2005). Consistent with the idea that NgR1 limits neuronal plasticity in the more mature nervous system, loss of physiological NgR1 signaling has been found to disrupt consolidation of synaptic connectivity in the visual system beyond the critical period (McGee et al., 2005). The underlying molecular mechanisms of enhanced anatomical plasticity after functional depletion of $\mathrm{NgR} 1$ in vivo, however, are mostly unknown. Finally, functional improvement in spinal cord-injured rodents treated with NgR1 antagonists is observed 1-2 weeks after injury (GrandPre et al., 2002; Li et al., 2005), which is likely to be too rapid to reflect true long-distance axonal regeneration (Steward et al., 2003). In future studies, it will be interesting to explore whether NgR1 participates in regulating short-range structural plasticity, such as dendritic spine architecture, thereby influencing synaptic connectivity and neuronal transmission.

Together, our data and those of Zheng et al. (2005) indicate that NgR1 is not necessary for neurite outgrowth inhibition elicited by any of its high-affinity myelin ligands, including the Nogo-A inhibitory peptide Nogo-66, OMgp, and MAG. Interestingly, we find that NgR1 is important to bring about growth cone collapse in the presence of soluble MAG or OMgp ectodomains. As discussed above, our findings do not rule out a physiological role for the known myelin inhibitor-NgR1 interactions; however, they fail to support the idea of NgR1 as an important receptor for myelin-mediated inhibition of longitudinal neurite extension. Finally, given the growing interest in NgR1 as a target for drug development in nervous system regeneration (Lee et al., 2003, 2004; Hu and Strittmatter, 2004; Satoh et al., 2005), it is our hope that the data presented here will help to focus ongoing efforts to further elucidate the full complement of receptors and 
molecular mediators of CNS myelin-mediated outgrowth inhibition.

\section{References}

Ahmed Z, Dent RG, Suggate EL, Barrett LB, Seabright RJ, Berry M, Logan A (2005) Disinhibition of neurotrophin-induced dorsal root ganglion cell neurite outgrowth on CNS myelin by siRNA-mediated knockdown of NgR, p75NTR and Rho-A. Mol Cell Neurosci 28:509-523.

Barrette B, Vallieres N, Dube M, Lacroix S (2007) Expression profile of receptors for myelin-associated inhibitors of axonal regeneration in the intact and injured mouse central nervous system. Mol Cell Neurosci 34:519-538.

Barton WA, Liu BP, Tzvetkova D, Jeffrey PD, Fournier AE, Sah D, Cate R, Strittmatter SM, Nikolov DB (2003) Structure and axon outgrowth inhibitor binding of the Nogo-66 receptor and related proteins. EMBO J 22:3291-3302.

Belhaj-Saif A, Cheney PD (2000) Plasticity in the distribution of the red nucleus output to forearm muscles after unilateral lesions of the pyramidal tract. J Neurophysiol 83:3147-3153.

Cafferty WB, Strittmatter SM (2006) The Nogo-Nogo receptor pathway limits a spectrum of adult CNS axonal growth. J Neurosci 26:12242-12250.

Cafferty WB, Kim JE, Lee JK, Strittmatter SM (2007) Response to correspondence: Kim et al., "axon regeneration in young adult mice lacking Nogo-a/b.” Neuron 38, 187-199. Neuron 54:195-199.

de Leon RD, Hodgson JA, Roy RR, Edgerton VR (1998) Locomotor capacity attributable to step training versus spontaneous recovery after spinalization in adult cats. J Neurophysiol 79:1329-1340.

Domeniconi M, Cao Z, Spencer T, Sivasankaran R, Wang K, Nikulina E, Kimura N, Cai H, Deng K, Gao Y, He Z, Filbin M (2002) Myelinassociated glycoprotein interacts with the Nogo66 receptor to inhibit neurite outgrowth. Neuron 35:283-290.

Fournier AE, GrandPre T, Strittmatter SM (2001) Identification of a receptor mediating Nogo-66 inhibition of axonal regeneration. Nature 409:341-346.

Fournier AE, Gould GC, Liu BP, Strittmatter SM (2002) Truncated soluble Nogo receptor binds Nogo-66 and blocks inhibition of axon growth by myelin. J Neurosci 22:8876-8883.

Giger RJ, Urquhart ER, Gillespie SKH, Levengood DV, Ginty DD, Kolodkin AL (1998) Neuropilin-2 is a receptor for semaphorin IV: insight into the structural basis of receptor function and specificity. Neuron 21:1079-1092.

GrandPre T, Li S, Strittmatter SM (2002) Nogo-66 receptor antagonist peptide promotes axonal regeneration. Nature 417:547-551.

Hofer T, Tangkeangsirisin W, Kennedy MG, Mage RG, Raiker SJ, Venkatesh K, Lee H, Giger RJ, Rader C (2007) Chimeric rabbit/human Fab and IgG specific for members of the Nogo-66 receptor family selected for species cross-reactivity with an improved phage display vector. J Immunol Methods 318:75-87.

Hu F, Strittmatter SM (2004) Regulating axon growth within the postnatal central nervous system. Semin Perinatol 28:371-378.

Kim JE, Liu BP, Park JH, Strittmatter SM (2004) Nogo-66 receptor prevents raphespinal and rubrospinal axon regeneration and limits functional recovery from spinal cord injury. Neuron 44:439-451.

Lamprecht R, LeDoux J (2004) Structural plasticity and memory. Nat Rev Neurosci 5:45-54.

Lee DH, Strittmatter SM, Sah DW (2003) Targeting the Nogo receptor to treat central nervous system injuries. Nat Rev Drug Discov 2:872-878.

Lee JK, Kim JE, Sivula M, Strittmatter SM (2004) Nogo receptor antagonism promotes stroke recovery by enhancing axonal plasticity. J Neurosci 24:6209-6217

Li S, Strittmatter SM (2003) Delayed systemic Nogo-66 receptor antagonist promotes recovery from spinal cord injury. J Neurosci 23:4219-4227.

Li S, Liu BP, Budel S, Li M, Ji B, Walus L, Li W, Jirik A, Rabacchi S, Choi E, Worley D, Sah DW, Pepinsky B, Lee D, Relton J, Strittmatter SM (2004) Blockade of Nogo-66, myelin-associated glycoprotein, and oligodendro- cyte myelin glycoprotein by soluble Nogo-66 receptor promotes axonal sprouting and recovery after spinal injury. J Neurosci 24:10511-10520.

Li S, Kim JE, Budel S, Hampton TG, Strittmatter SM (2005) Transgenic inhibition of Nogo-66 receptor function allows axonal sprouting and improved locomotion after spinal injury. Mol Cell Neurosci 29:26-39.

Liu BP, Fournier A, GrandPre T, Strittmatter SM (2002) Myelin-associated glycoprotein as a functional ligand for the Nogo-66 receptor. Science 297:1190-1193.

Liu BP, Cafferty WB, Budel SO, Strittmatter SM (2006) Extracellular regulators of axonal growth in the adult central nervous system. Philos Trans R Soc Lond B Biol Sci 361:1593-1610.

McGee AW, Yang Y, Fischer QS, Daw NW, Strittmatter SM (2005) Experience-driven plasticity of visual cortex limited by myelin and Nogo receptor. Science 309:2222-2226.

Raineteau O, Schwab ME (2001) Plasticity of motor systems after incomplete spinal cord injury. Nat Rev Neurosci 2:263-273.

Reza JN, Gavazzi I, Cohen J (1999) Neuropilin-1 is expressed on adult mammalian dorsal root ganglion neurons and mediates semaphorin3a/ collapsin-1-induced growth cone collapse by small diameter sensory afferents. Mol Cell Neurosci 14:317-326.

Satoh J, Onoue H, Arima K, Yamamura T (2005) Nogo-A and nogo receptor expression in demyelinating lesions of multiple sclerosis. J Neuropathol Exp Neurol 64:129-138.

Sivasankaran R, Pei J, Wang KC, Zhang YP, Shields CB, Xu XM, He Z (2004) PKC mediates inhibitory effects of myelin and chondroitin sulfate proteoglycans on axonal regeneration. Nat Neurosci 7:261-268.

Steward O, Zheng B, Tessier-Lavigne M (2003) False resurrections: distinguishing regenerated from spared axons in the injured central nervous system. J Comp Neurol 459:1-8.

Steward O, Zheng B, Banos K, Yee KM (2007) Response to: Kim et al., "Axon regeneration in young adult mice lacking Nogo-A/B." Neuron 38, 187-199. Neuron 54:191-195.

Toni N, Buchs PA, Nikonenko I, Bron CR, Muller D (1999) LTP promotes formation of multiple spine synapses between a single axon terminal and a dendrite. Nature 402:421-425.

Vaynman S, Gomez-Pinilla F (2005) License to run: exercise impacts functional plasticity in the intact and injured central nervous system by using neurotrophins. Neurorehabil Neural Repair 19:283-295.

Venkatesh K, Chivatakarn O, Lee H, Joshi PS, Kantor DB, Newman BA, Mage R, Rader C, Giger RJ (2005) The Nogo-66 receptor homolog NgR2 is a sialic acid-dependent receptor selective for myelin-associated glycoprotein. J Neurosci 25:808-822.

Venkatesh K, Chivatakarn O, Sheu SS, Giger RJ (2007) Molecular dissection of the myelin-associated glycoprotein receptor complex reveals cell typespecific mechanisms for neurite outgrowth inhibition. J Cell Biol 177:393-399.

Wang KC, Koprivica V, Kim JA, Sivasankaran R, Guo Y, Neve RL, He Z (2002a) Oligodendrocyte-myelin glycoprotein is a Nogo receptor ligand that inhibits neurite outgrowth. Nature 417:941-944.

Wang KC, Kim JA, Sivasankaran R, Segal R, He Z (2002b) p75 interacts with the Nogo receptor as a co-receptor for Nogo, MAG and OMgp. Nature 420:74-78.

Wang X, Baughman KW, Basso DM, Strittmatter SM (2006) Delayed Nogo receptor therapy improves recovery from spinal cord contusion. Ann Neurol 60:540-549.

Yamashita T, Higuchi H, Tohyama M (2002) The p75 receptor transduces the signal from myelin-associated glycoprotein to Rho. J Cell Biol 157:565-570.

Yu P, Huang L, Zou J, Zhu H, Wang X, Yu Z, Xu XM, Lu PH (2007) DNA vaccine against $\mathrm{NgR}$ promotes functional recovery after spinal cord injury in adult rats. Brain Res 1147:66-76.

Zheng B, Atwal J, Ho C, Case L, He XL, Garcia KC, Steward O, TessierLavigne M (2005) Genetic deletion of the Nogo receptor does not reduce neurite inhibition in vitro or promote corticospinal tract regeneration in vivo. Proc Natl Acad Sci USA 102:1205-1210. 